\title{
Factors associated with the unresolved classification of the Adult Attachment Interview in women who have suffered stillbirth
}

\author{
P. HUGHES ${ }^{a}{ }^{\text {P. TURTON }},{ }^{a}$ E. HOPPER,${ }^{a}$ G. A. MCGAULEY, ${ }^{a}$ \\ AND P. FONAGY ${ }^{b}$ \\ ${ }^{a}$ St. George's Hospital Medical School, London; and ${ }^{b}$ University College London
}

\begin{abstract}
The "unresolved" state of mind with respect to loss or trauma as assessed in the Adult Attachment Interview is common in clinical and forensic groups, as well as in mothers whose infants are classified as disorganized in their attachment relationship to them. However, questions remain about what the unresolved state represents and what factors predict the unresolved state. This case controlled study reports on 64 women who had suffered stillbirth and who were pregnant with their next child. The study explores attachment, psychiatric, and social factors associated with the unresolved state or higher unresolved scores with respect to stillbirth. Women who had experienced stillbirth were more likely to be unresolved than control women. Although a similar number of stillbirth and control women had experienced childhood trauma, only women who had experienced stillbirth were unresolved with respect to this trauma, suggesting the unresolved state may be evoked or reevoked by subsequent traumatic loss. Higher unresolved scores in relation to stillbirth were predicted by childhood trauma, poor support from family after the loss, and having a funeral for the infant. The results are discussed in terms of the woman's sense of being causal in the loss.
\end{abstract}

Although Bowlby's descriptive accounts (1969/1982) of the attachment needs of adults were both impressive and convincing, systematic research into adult representation of attachment only became possible with the development of the Adult Attachment Interview (AAI) in 1985 (Main \& Goldwyn, 1985-

This study was funded by South Thames West R\&D, Tommy's Campaign, and the Simenauer Trust (Institute of Psycho-Analysis, London). We thank the Editor and four anonymous referees for their extremely helpful suggestions, many of which we adopted. We also thank the nursing and medical staff and the mothers who generously gave their time to the study.

Address correspondence and reprint requests to: Dr. P. Hughes, Department of Psychiatry, St. George's Hospital Medical School, Cranmer Terrace, London SW17 ORE, UK; E-mail: p.hughes@sghms.ac.uk.
1995; Main, Kaplan, \& Cassidy, 1985). The original three categories were defined by their relationship to already established infant categories, and subsequent meta-analysis confirmed correspondence between infant and adult secure and insecure categories (van IJzendoorn, 1995). At this earlier stage in the use of the AAI, many researchers observed that some people showed unusual discourse in the discussion of loss of an attachment figure. Researchers also noted that odd, hard to classify behavior of infants in the Strange Situation seemed to be associated with parental early loss of an attachment figure (R. Goldwyn, personal communication). The recognition of infant behavior that was hard to fit into the secure/insecure categories led to the important discovery that infant behavior could 
be assessed for the parameter of organized or disorganized, as well as secure or insecure (Main \& Solomon 1986, 1990).

The specific characteristics that defined the unresolved classification in the AAI were outlined in 1991 (Main, DeMoss, \& Hesse, 1991). Careful analysis of the AAI revealed that mothers of children classified as disorganized made characteristic lapses in the monitoring of discourse or of reasoning when discussing attachment-related loss or trauma (Main et al., 1991; Main \& Hesse, 1990). The coding of the unresolved status is separate from the rest of the AAI coding system and therefore an individual's narrative might be considered secure ( $F$ or autonomous), entangled $(E)$, or dismissing $(D s)$ on the basis of the rest of the interview and either resolved or unresolved specifically on the basis of parts of the narrative relating to particular loss or traumatic experiences. This parentinfant link was experimentally supported in 1991 (Ainsworth \& Eichberg, 1991; Fonagy, Steele, \& Steele, 1991) and later nine studies (both cross-sectional and prospective) of 548 infant-mother pairs found an association between disorganization of infant attachment and evidence of "unresolved" discourse relating to attachment-related loss or abuse in the parent's AAI (van IJzendoorn, 1995). The discourse pattern initially designated unresolved, was later described as "disorganized/disorientated" with respect to loss or trauma (Main \& Hesse, 1990, 1992), emphasizing that it was the mental representation of the loss or trauma and not the experience itself that was thought to be interfering with caregiving behavior in some way.

The unresolved state of mind is more common in clinical groups (Fonagy, Leigh, Steele, Steele, Kennedy, Mattoon, Target, \& Gerber, 1996; Patrick, Hobson, Castle, Howard, \& Maughan, 1994; van IJzendoorn \& BakermansKranenburg, 1996) and in forensic populations (van IJzendoorn, Feldbrugge, Derks, deRuiter, Verhagen, Philipse, Van der Staak, \& RiksenWalraven, 1997), and older people are more likely than younger to be unresolved (Benoit \& Parker, 1994). It seems likely that this may be partly explained by a higher than usual experience of trauma in forensic and clinical popula- tions and lifetime loss in older people. There has been interest in exploring the nature of the unresolved state and some evidence that it represents a dissociative state (Hesse \& van IJzendoorn, 1998, 1999; Liotti, 1992). However, questions remain about precisely what the "unresolved" state of mind represents, how it comes about, what factors promote or inhibit its development, and how it relates to the affective symptoms resulting from loss or trauma.

\section{Can We Standardize Loss?}

To date, studies of the unresolved state have looked at the effect of heterogeneous experiences that met stated criteria for loss or trauma. All studies but one identified loss or trauma in unselected, naturalistic populations; in the one study that selected subjects on the basis of having experienced loss (Schuengel, Bakermans-Kranenburg, \& van IJzendoorn, 1999), the operational definition of an attachment figure included anyone the individual had seen on a regular weekly basis. Clearly, there is considerable variation in the meaning of a loss and the degree to which it is experienced as traumatic in disparate situations. The nature of the loss and lack of resolution are thus confounded, with more serious or more traumatic losses perhaps being more likely to not be resolved (although this has not been investigated systematically to our knowledge).

One way of furthering the understanding of factors associated with a person being unresolved is with a quasiexperimental design in which individuals who have had a particular loss or trauma are compared to a sample who have experienced the usual naturalistic range of losses/traumas. If we can restrict the variability around the loss/trauma, it offers the opportunity to examine demographic and psychological factors that may contribute to a person being unresolved or that link to the unresolved classification in a way that furthers our understanding of the meaning of this state of mind. Our ideal is to find a loss or trauma in which the individual's personality, attitude, or behavior will have played little or no part in its causation and whose impact is likely to be universally severe and traumatic. 
Earlier studies of the relationship between loss and the unresolved state suggested that loss during childhood was important, but over time researchers have implicitly assumed that any important loss may lead to the unresolved state (e.g., Bakermans-Kranenburg, Schuengel, \& van IJzendoorn, 1999). Moreover, the AAI requires the interviewer to probe all losses, including recent losses (Main \& Goldwyn, 1985-1995). We are not aware of definitive evidence that loss early in life, or more recently, has a greater or lesser effect on attachment representation.

One serious loss that affects people of childbearing age is stillbirth. This traumatic loss is almost always unexpected and involves physical pain and emotional shock for the mother. Stillbirth occurs in about $0.5 \%$ of all births after 24 weeks of gestation in the United Kingdom (Office for National Statistics, 1998). Most parents suffer symptoms of depression for many months afterward (Hughes, Turton, \& Evans, 1999; Janssen, Cuisinier, de Graauw, \& Hoogduin, 1997). There are three published studies of attachment after pregnancy loss. Two studies of perinatal loss reported a significant increase in disorganized attachment (Heller \& Zeanah, 1999; Hughes, Turton, Hopper, McGauley, \& Fonagy, 2001); and a study of early miscarriage found unresolved scores related to gestation, although few women were classified as unresolved (Bakermans-Kranenburg et al., 1999). During the last 25 years, psychosocial management of stillbirth has changed. Previously, the infant was immediately removed to protect parents from further distress. Now parents are encouraged to see and hold the body and to have a funeral (Royal College of Obstetricians and Gynaecologists, 1985), in the belief that this will facilitate mourning. A study of women who have suffered stillbirth may therefore offer an opportunity to explore circumstances that protect from unresolvedness or increase vulnerability and allow us to explore the relationship between unresolved and other factors in the individual's life.

In this article we have followed the recommendation of Zeanah (1989) in distinguishing grief, the painful affective symptoms that follow loss, from the process of mourning, the complex psychological processes triggered by the loss, that ultimately should lead to recovery. Although Bowlby (1980) suggested a link between the affective process of grieving and mental reorganization following loss, there are no data on whether affective symptoms are associated with the unresolved state of mind and, although affective symptoms of grief are reduced with time (Janssen et al., 1997), we do not know whether indices of the unresolved state fall in parallel with these.

Our hypotheses were the following:

1. Stillbirth experience is associated with the characteristic disorganized thinking of the unresolved state as measured in the AAI.

2. If this is so, this will be accounted for by (a) greater social disadvantage in the stillbirth group, (b) lower levels of attachment security in the stillbirth group, and (c) a greater number of losses in the stillbirth group. We hypothesize that the stillbirth experience interacts with these background factors to increase the likelihood of unresolved status.

3. Women who experienced stillbirth are more likely to be unresolved with respect to previous trauma or loss compared to woman who had not suffered a stillbirth.

4. Background factors protect or sensitize an individual to the disorganizing effect of stillbirth: (a) secure attachment protects the individual from the disorganizing impact of a loss, (b) earlier trauma or loss sensitizes an individual and makes her more likely to become unresolved after stillbirth, and (c) a history of additional early pregnancy loss through miscarriage or elective termination of pregnancy is associated with greater likelihood of being unresolved for stillbirth.

5. The gestation and recency of stillbirth loss is associated with being unresolved for stillbirth. If this is so, it will be accounted for by symptoms of grief.

6. Social support, either from partner or family, mitigates the lack of resolution.

7. Practices that encourage contact with the body of the stillborn child relate to whether a woman is likely to become unresolved. 


\section{Method}

\section{Study design}

This is a case controlled study of a group of childless pregnant women whose previous pregnancy ended in stillbirth and a control group of primigravid women. Over $90 \%$ of births in the United Kingdom take place in public hospitals (District General Hospitals) and almost all women attend their local hospital, with the first visit at 13 weeks of gestation. To identify consecutive women who met the criteria for the study, we screened the case notes of all women attending prenatal clinics at three District General Hospitals every 3-4 months during the period of recruitment. Because the previous obstetric history is recorded in the notes, this proved an effective way to identify possible subjects. Therefore, the study is effectively a population-based study.

The AAI was conducted and demographic and psychiatric data were gathered from mothers in the third trimester.

\section{Subjects}

The index subjects were 64 women whose previous pregnancy (or pregnancies) had ended in spontaneous loss after 18 weeks of gestation. We chose this cutoff because, when defining stillbirth, clinicians tend to use parents' experience of their baby's maturity as a guide and generally recognize a loss in the second half of pregnancy as representing a lost child to the parents. Eighteen weeks is the gestational age when mothers typically detect fetal movement, and babies are normally delivered in the labor ward rather than the gynecology ward after this date. Sixty of these women were case matched for age, ethnicity, and educational level to a control group of 60 primigravid women attending the same clinics. The participating women were over 20 years of age, had a single pregnancy, had a partner, spoke enough English to complete the AAI, and had no live children. We excluded women who were in treatment for acute physical or mental illness or if the stillbirth had been a termination for abnormality.
Approximately 30,000 prenatal case records were examined and $82(85 \%)$ of the 96 women whose previous pregnancy ended in stillbirth and who met the inclusion criteria agreed to participate. We planned interviews for the second half of the third trimester but, as might be expected in this group, 13 women (14\%) gave birth before the time arranged for the first interview. Sixty-nine (72\%) women had a third trimester interview, but the data from five interviews were too incomplete to be useful. Sixty-four subjects had complete data from the third trimester assessment, which is $67 \%$ of the 96 who originally met the criteria.

Eighty-three control women were identified. Of these, $63(76 \%)$ agreed to participate, one of whom gave birth before the interview. Sixty-two had a third trimester interview with complete data, which is $75 \%$ of the 83 who met the criteria. Among the women in each group there were 60 matched pairs.

Thirty-nine pairs of index and control women were White, and 21 pairs were from ethnic minority groups with exact matching between subjects and controls. There were no significant between-group differences on age, educational level achieved, length of time with partner, or reported previous physical or mental illness. We noted the number of losses of an attachment figure that each participant had experienced. Fifty-three women who had experienced stillbirth reported other loss of an attachment figure, and 55 control women had lost an attachment figure (20 index and 13 control women had 1 loss other than stillbirth; 21 index and 25 control had 2 losses; 12 index and 17 control had 3 or more losses; index vs. control, exact $p=.39$ ). Thirteen women who had experienced stillbirth and 11 control women reported trauma (physical or sexual abuse) relating to an attachment figure in childhood. Thus, the groups were relatively well matched for both previous losses and trauma.

In cases where the analysis is relevant only to the women who experienced stillbirth, we used all 64 with complete AAI data. Nine index women with previous elective termination of pregnancy and 19 with additional early miscarriage showed no significant differences from other subjects on baseline variables. 
Among the 64 women, 25 (39\%) had had a third trimester loss and $39(61 \%)$ a second trimester loss. Six (9\%) reported the stillborn infant had a congenital abnormality, and the remainder were told the infant was normal. None reported psychiatric treatment after the stillbirth. Thirty-three (52\%) women conceived at $<12$ months and $31(48 \%)$ at $>12$ months after the stillbirth (range $=2-177$ months, mean $=21$ months, median $=9.5$ months).

\section{Procedure}

The procedure had Local Ethics Committees' approval. After suitable women were identified, the progress in the pregnancy was monitored using case records to ensure we did not approach a woman who had lost her pregnancy or developed complications. Women were contacted in the third trimester when the pregnancy outcome was likely to be healthy. Written informed consent was obtained from the participants. Assessments took place either in the hospital outpatient department or the woman's home.

\section{Instruments}

Demographic information came from two sources. Data relating to the mother's pregnancy and previous health came from her hospital health records and additional data were collected at the interviews. An observercompleted demographic questionnaire confirmed social history (education, self and partner's employment, income, housing, previous physical, and mental illness), additional experience of pregnancy loss from early miscarriage or elective termination of pregnancy, and details of the stillbirth loss (gestation of loss, time since loss, psychosocial interventions at the time of loss, family and partner support). The analysis of social disadvantage variables (neither self nor partner employed, low income, and unsatisfactory housing) showed they were highly correlated (Cronbach's $\alpha=.65$ ). We therefore used an ordinal social disadvantage measure, summing the above items. Following a wellestablished epidemiological tradition (Rutter
\& Quinton, 1977), disadvantage was considered additive rather than specific and subjects were rated 1 if they had no disadvantages, 2 if they had one, and 3 if they had more than one. Subject and control women were initially matched on the basis of information in their hospital case notes. However, although the groups proved to be well matched on other social criteria, the interview revealed significant differences in social disadvantage between subject and control groups, with nine subjects and no controls having more than one disadvantaging factor (exact $p=.005$ ). We therefore included assessment of the effect of social disadvantage in all relevant analyses.

The AAI (Main \& Goldwyn, 1985-1995) was utilized in this study. Because women who had suffered stillbirth knew that the study was related to their pregnancy loss, it would have been insensitive to ignore this in the AAI. We therefore began the section on loss by saying "I want to ask you about your experience of loss. I know you lost your last baby late in pregnancy . . . can you tell me about it." When discussion of the stillbirth was complete, the interviewer proceeded to ask about other loss as in a standard AAI. Miscarriage and elective termination of pregnancy were not explored in the AAI as significant losses, so the results do not include a score for unresolved relating to these experiences. The standard AAI was administered to control women. The transcribed AAI was rated 2-way (secure vs. insecure, $F$ vs. $D s$ and $E), 3$-way $(F, D s, E)$ and 4-way to include the unresolved $(U)$ as a fourth category. A score was given for evidence of unresolved discourse on a 1-9 point scale, with 5.5 or greater rated as unresolved; transcripts rated 5 were reviewed by the two raters and the most appropriate category was agreed upon. Separate scores for unresolved discourse relating to the stillbirth $\left(U_{\mathrm{sb}}\right)$ and for unresolved discourse relating to other loss $\left(U_{\text {loss }}\right)$ or trauma $\left(U_{\mathrm{tr}}\right)$ were allocated, and the overall unresolved score $\left(U_{\mathrm{o}}\right)$ was the highest of these (Main \& Goldwyn, 1985-1995). Forty percent of the transcripts were double rated. The interrater reliability for the 4-way classification was $\kappa=$ .63 and for the unresolved versus resolved categories was $\kappa=.71$. The interrater reliability 
for continuous $U_{\mathrm{o}}$ scores was $26 \%$ perfect agreement and $87 \%$ within 1.5 points on the 9 -point scale $(r=.69, \tau b=.57, p<.0005)$. In the case of disagreement between raters the transcript was conferenced, with a third rater included if necessary, and the most appropriate category chosen. All three raters were trained by Mary Main and Erik Hesse and confirmed as reliable for 3-way and 4-way classification. The content of the interview precluded blinding the transcripts.

The Edinburgh Postnatal Depression Scale (EPDS) is a 10-item self-report scale to assess depression that was developed and validated for postnatal use. The sensitivity of the EPDS was reported as $86 \%$ and the specificity as $78 \%$. The split half reliability was 0.88 , and the standardized alpha coefficient was 0.87 (Cox, Holden, \& Sagovsky, 1987). Evaluations of the EPDS against the Beck Depression Inventory in the first 6 months postpartum (Harris, Huckle, Thomas, Johns, \& Fung, 1989; Lee, Wong, Ungvari, Cheung, Haines, \& Chung, 1997; Lee, Yip, Chiu, Leung, Chan, Chau, Leung, \& Chung, 1998; Pop, Komproe, \& Van Son, 1992; Stuart, Couser, Schilder, O'Hara, \& Gorman, 1998) report a correlation $(r)$ between .59 and .78 . The EPDS is extensively used in the United Kingdom, and it is validated for use in pregnancy (Murray \& Cox, 1990). For dichotomous analysis the $14 / 15$ cutoff was used prenatally (as recommended by Murray and Cox because of the high levels of dysphoria in pregnancy) and for measurement at 6 and 26 weeks the conventional 12/13 cutoff was used.

The Spielberger State-Trait Inventory is a 40-item questionnaire measuring anxiety at time of testing (state) and the general tendency to anxiety (trait). Each item is scored from 0 (no symptoms) to 4 . The average score for a nonclinical, working, female population has been reported as 35 ( $S D=10.6$; Spielberger, Gorsuch, \& Lushene, 1970). The correlation coefficients for females ranged from .34 for female state anxiety after 30 days to .75 for female trait anxiety after 60 days. The Cronbach's alpha coefficients of internal consistency showed that all but one of the state anxiety alphas were above .9 with a median coefficient of .93. The trait anxiety alpha co- efficients were also consistently high with a median coefficient of 0.9 (Spielberger et al., 1970).

\section{Statistical Analysis}

Unresolved loss was considered as both a categorical and continuous variable. In the first part of the analysis where we compared index and control women, we used the overall unresolved status $\left(U_{\mathrm{o}}\right)$ and $U_{\mathrm{o}}$ score as the dependent variables. In the second section of the analysis we used the unresolved status and score relating to the stillbirth $\left(U_{\mathrm{sb}}\right)$ or, where relevant, to the experience of childhood trauma $\left(U_{\mathrm{tr}}\right)$.

The association of each predictor variable with the categorical measure of unresolved was examined using the univariate statistics chi square or $t$ test as appropriate. Contingency table analyses that involve the comparison group used hierarchical loglinear analysis to test if the impact of the predictor variable on the unresolved status was comparable for the two groups. Differential impact was thought to be indicated by the three-way interaction term being required in order to appropriately model the observed frequencies. A backward elimination procedure was implemented to identify the simplest best-fitting model. Hierarchical logistic regressions were performed to control for the impact of confounding categorical variables on unresolved classification, and multiple linear regressions were used when dependent variables were continuous.

\section{Results}

The results are organized in terms of the research hypotheses.

Hypothesis 1: Does stillbirth lead to the characteristic disorganized thinking of the unresolved state as measured in the AAI? Does insecure attachment or childhood trauma interact with stillbirth experience in making an individual more likely to be unresolved?

Table 1 displays the number of women who were categorized as unresolved $\left(U_{\mathrm{o}}\right)$, who are grouped according to stillbirth history and according to their major attachment category $(F$, 
Table 1. Number of women whose interviews received an unresolved classification according to major AAI classification in stillbirth and control groups, unresolved category

\begin{tabular}{|c|c|c|c|c|}
\hline AAI Classification & $\begin{array}{c}\text { Total Across } \\
\text { Attachment Classes }\end{array}$ & $F$ & $D$ s & E \\
\hline Stillbirth women & $35(58 \%)$ & $15(43 \%)$ & $13(37 \%)$ & $7(20 \%)$ \\
\hline Interviews classified unresolved & $\begin{array}{l}+3.4 \\
25(42 \%)\end{array}$ & $\begin{array}{l}-0.04 \\
11(44 \%)\end{array}$ & $\begin{array}{l}-0.56 \\
13(52 \%)\end{array}$ & $\begin{array}{l}1.08 \\
1(4 \%)\end{array}$ \\
\hline Interviews not classified unresolved & -2.4 & $\begin{array}{l}-0.05 \\
26(43 \%)\end{array}$ & $\begin{array}{l}0.66 \\
26(43 \%)\end{array}$ & $\begin{array}{l}-1.28 \\
8(13 \%)\end{array}$ \\
\hline Total stillbirth interviews $(n=60)$ & & -1.1 & 0.6 & 1.3 \\
\hline Control women & $5(8 \%)$ & $3(60 \%)$ & $2(40 \%)$ & $0(0 \%)$ \\
\hline Interviews classified unresolved & $\begin{array}{l}-3.4 \\
55(92 \%)\end{array}$ & $\begin{array}{l}-0.09 \\
35(64 \%)\end{array}$ & $\begin{array}{l}0.26 \\
18(33 \%)\end{array}$ & $\begin{array}{l}-0.41 \\
2(4 \%)\end{array}$ \\
\hline Interviews not classified unresolved & 2.4 & $\begin{array}{l}0.03 \\
38(63 \%)\end{array}$ & $\begin{array}{l}-0.08 \\
20(33 \%)\end{array}$ & $\begin{array}{l}0.12 \\
2(3.3 \%)\end{array}$ \\
\hline Total control interviews $(n=60)$ & & 1.1 & -0.60 & -1.3 \\
\hline
\end{tabular}

Note: The italic values are standardized residuals.

$D s, E)$. Thirty-five $(58 \%)$ women who had suffered stillbirth were $U_{\mathrm{o}}$ compared to $5(8 \%)$ control women. A 4-way analysis including the unresolved category showed a highly significant difference between groups, $\chi^{2}(3, N=$ $120)=38.59, p<.0001$.

A hierarchical log linear analysis was done to see if unresolved interviews were more common in individuals from specific attachment categories. The three-way association (group, AAI class, unresolved classification) was insignificant and eliminated from the model, $\chi^{2}(2, N=$ $120)=1.59, n s$. Of the two-way associations only Group $\times$ Unresolved Classification, $\chi^{2}(1$, $N=120)=36.84, p<.0001$, and Group $\times$ AAI Class, $\chi^{2}(2, N=120)=6.90, p<.04$, needed to be retained in the model to obtain an acceptable fit, $\chi^{2}(4, N=120)=4.43, n s$. Thus, the relatively weak association between attachment class and stillbirth status is independent of the overrepresentation of the unresolved classification in the index group and is accounted for by a slight underrepresentation of secure interviews in the stillbirth group.

The AAI transcripts were coded for unresolved state of mind with respect to stillbirth, unresolved with respect to childhood trauma, and unresolved with respect to other loss of attachment figure. Thirty four of the 35 unresolved interviews in the stillbirth group were coded $U_{\mathrm{sb}}$. Of these, 24 were coded unresolved solely with respect to the stillbirth $\left(U_{\mathrm{sb}}\right) ; 6$ were $U_{\mathrm{sb}}$ and $U_{\mathrm{tr}} ; 3$ were $U_{\mathrm{sb}}$ and $U_{\text {loss }}$; one was $U_{\mathrm{sb}}, U_{\mathrm{tr}}$, and $\mathrm{U}_{\text {loss }}$; and 1 was only $U_{\text {loss }}$ (see Table 2 ). All but 3 women in the stillbirth group who reported other loss/ trauma had their highest unresolved score for the stillbirth. These analyses suggest that by far the most important factor associated with the overrepresentation of unresolved status in the stillbirth group was the loss of the baby.

We wanted to know if the current unresolved status $\left(U_{\mathrm{o}}\right)$ was more likely in women who had experienced childhood trauma. The hierarchical loglinear analysis including experience of stillbirth, childhood trauma, and $U_{\mathrm{o}}$ status yielded a significant three-way effect for the association, likelihood ratio $\chi^{2}$ $(1, N=119)=7.38, p<.007$. It seems that childhood trauma increases the chance of a $U_{\mathrm{o}}$ classification but only in women who had suffered the subsequent traumatic loss of stillbirth.

Hypothesis 2: Is unresolved status in stillbirth and control women accounted for by social disadvantage, attachment security, and number of losses?

We found that there was greater social disadvantage, somewhat less attachment security, and greater number of losses (if including stillbirth) in the stillbirth group. We therefore 
Table 2. Unresolved status and scores for stillbirth, other loss, and trauma in Adult Attachment Interviews of stillbirth and control women

\begin{tabular}{|c|c|c|c|c|}
\hline & \multicolumn{2}{|c|}{ Stillbirth Group $(n=60)$} & \multicolumn{2}{|c|}{ Control Group $(n=60)$} \\
\hline & Frequency & Mean $U$ Score & Frequency & Mean $U$ Score \\
\hline $\begin{array}{l}\text { Overall interviews classified } \\
\text { unresolved }\left(U_{\mathrm{o}}\right)\end{array}$ & $35(58 \%)$ & $5.7(1.8)$ & $5(8 \%)$ & $3.3(1.4)$ \\
\hline $\begin{array}{l}\text { Unresolved with respect to } \\
\text { stillbirth }\left(U_{\mathrm{sb}}\right)\end{array}$ & $34(57 \%)$ & $5.6(1.9)$ & NA & NA \\
\hline $\begin{array}{l}\text { No. with loss of other } \\
\text { attachment figure }\end{array}$ & $53(88 \%)$ & & $55(92 \%)$ & \\
\hline $\begin{array}{l}\text { No. unresolved with respect to } \\
\text { other loss }\left(U_{\text {loss }}\right)\end{array}$ & $5(8 \%$ of 60$)$ & $3.2(1.6)$ & $5(8 \%$ of 60$)$ & $3.3(1.3)$ \\
\hline No. $U_{\text {loss }}$ and $U_{\mathrm{sb}}$ & $4(7 \%$ of 60$)$ & & NA & \\
\hline $\begin{array}{l}\text { No. with trauma related to } \\
\text { attachment figure }\end{array}$ & $13(22 \%)$ & & $11(18 \%)$ & \\
\hline $\begin{array}{l}\text { No. unresolved with respect to } \\
\text { trauma }\left(U_{\text {tr }}\right)\end{array}$ & $7(54 \%$ of 13$)$ & $4.8(1.9)$ & 0 & $2.6(1.2)$ \\
\hline $\begin{array}{l}\text { No. with trauma experience and } \\
U_{\mathrm{sb}}\end{array}$ & $12(92 \%$ of 13$)$ & & NA & \\
\hline
\end{tabular}

examined whether the $U_{\mathrm{o}}$ classification was predicted by the experience of stillbirth when these variables were controlled for. A hierarchical logistic regression was performed using the $U_{\mathrm{o}}$ classification as the dependent variable with social disadvantage entered in the first block of predictors, $\chi^{2}(1, N=118)=4.1$, $p<.05)$, attachment security in the second block, $\chi^{2}(1, N=118)=1.6, n s$, number of losses including stillbirth in the third block, $\chi^{2}(1, N=118)=4.3, p<.04$, and experience of stillbirth in the fourth block, $\chi^{2}(1$, $N=118)=27.5, p<.0001$.

The odds ratio for the unresolved classification associated with the experience of stillbirth was 14.9 (95\% confidence interval $=4.6-$ 48.4), indicating that the impact of stillbirth was substantial even after controlling for the effect of social disadvantage, attachment security, and number of losses.

To exclude the possibility that the experience of stillbirth simply meant that index women suffered more losses than control women, we examined the association between probability of $U_{\mathrm{o}}$ status and number of losses reported, excluding subjects who had no losses. Those with larger numbers of losses were no more likely to be coded $U_{\mathrm{o}}$. This shows that it was not simply the number of losses but spe- cifically the stillbirth that led to the increase in the probability of $U_{\mathrm{o}}$ status $\left(\tau_{\mathrm{B}}=-0.06\right.$, $N=114 ; p<.44)$.

Hypothesis 3: Were women who experienced stillbirth more likely to be unresolved with respect to previous trauma or loss compared to woman who had not suffered a stillbirth?

Stillbirth and control mothers reported similar numbers of experiences of childhood trauma (Table 2), but women in the stillbirth group were significantly more likely to be coded unresolved with respect to the trauma $\left(U_{\text {tr }}\right)$. Of 13 mothers in the stillbirth group who had childhood trauma, 7 were $U_{\text {tr }}$ whereas none of the 11 mothers in the control group who had childhood trauma were $U_{\text {tr }}$ (Fisher's two tailed, $p<.005)$. This suggests that women who are unresolved with respect to childhood trauma are more susceptible to experiencing stillbirth or the stillbirth evokes or reevokes the unresolved state in relation to past trauma.

Stillbirth and control mothers also reported similar numbers of experiences of loss other than stillbirth, but we did not find a difference in $U_{\text {loss }}$ between the groups. Of 53 stillbirth mothers who had lost one or more attachment 
Table 3. Relationship between categorical social factors and unresolved scores with respect to stillbirth $(S B)$

\begin{tabular}{lccccc}
\hline \hline Social Variable & Present $(n)$ & No. Unres. SB & Exact $p$ & $U_{\text {sb }}$ Score $(S D)$ & Significance \\
\hline See baby & Yes (48) & $30(63 \%)$ & .09 & $5.7(1.8)$ & $t(62)=1.38 ;$ \\
Hold baby & No (16) & $6(38 \%)$ & & $5.0(2.0)$ & $p=.17$ \\
& Yes (34) & $23(68 \%)$ & .08 & $6.0(1.6)$ & $t(62)=2.47 ;$ \\
Funeral & No (30) & $13(43 \%)$ & & $4.9(1.9)$ & $p<.02^{*}$ \\
& Yes (38) & $27(71 \%)$ & $<.006^{*}$ & $6.2(1.5)$ & $t(62)=3.97 ;$ \\
Family support & No (26) & $9(35 \%)$ & & $4.5(1.8)$ & $p<.0001^{*}$ \\
& Yes (48) & $21(44 \%)$ & $<.002^{*}$ & $5.1(1.8)$ & $t(61)=3.19 ;$ \\
Partner support & No (15) & $14(93 \%)$ & & $6.7(1.4)$ & $p<.002^{*}$ \\
& Yes (45) & $25(56 \%)$ & 1.00 & $5.6(1.8)$ & $t(61)=-0.50 ;$ \\
Trimester of loss & No (18) & $10(56 \%)$ & & $5.3(1.9)$ & $p=.61$ \\
& 2nd (39) & $19(49 \%)$ & .18 & $5.1(1.9)$ & $t(62)=-2.2 ;$ \\
Prev. miscarr & 3rd (25) & $17(68 \%)$ & & $6.1(1.6)$ & $p<.04^{*}$ \\
& Yes (19) & $11(58 \%)$ & 1.00 & $5.3(1.4)$ & $t(61)=-0.73 ;$ \\
Prev. term. of preg & No (44) & $25(57 \%)$ & & $5.7(2.0)$ & $p=.47$ \\
& Yes (9) & $7(78 \%)$ & .28 & $6.7(1.9)$ & $t(61)=2.08 ;$ \\
& No (54) & $29(54 \%)$ & & $5.4(1.8)$ & $p<.05^{*}$ \\
\hline \hline
\end{tabular}

$*$ Significant at $p<.05$.

figures other than the stillbirth, $5(9 \%)$ were unresolved with respect to a loss. Of the 55 control mothers who had lost an attachment figure, the same number, $5(9 \%)$, were unresolved with respect to a loss.

Hypothesis 4: Can we identify background factors (AAI class, other loss or trauma) that protect or sensitize women to the disorganizing effect of stillbirth?

Table 1 displays the number of women who were $U_{\mathrm{sb}}$ divided into three attachment categories. We sought to establish whether the attachment class was associated with being categorized as $U_{\mathrm{sb}}$. Neither 2-way, $\chi^{2}(1, N=$ $60)<1, n s$, nor 3-way, $\chi^{2}(2, N=60)=3.6$, $n s$, attachment classification was associated with $U_{\mathrm{sb}}$.

Table 2 displays the frequency of individuals reporting losses of attachment figures or of childhood trauma and the number coded unresolved in relation to these, as well as those coded $U_{\mathrm{sb}}$. The experience of childhood trauma appeared to increase the likelihood of being coded $U_{\mathrm{sb}}$. Although about half of the women (23 of 47) without childhood trauma were $U_{\mathrm{sb}}$, almost all (12 [92\%] of 13) who reported childhood trauma were $U_{\mathrm{sb}}(p<.005$, Fisher's ex- act). Further exploration indicated that it was the experience of trauma rather than its failed resolution that was associated with being $U_{\mathrm{sb}}$. Among the 13 stillbirth mothers who reported trauma, the 7 who were $U_{\text {tr }}$ were also $U_{\mathrm{sb}}$, and 5 of 6 who were not $U_{\mathrm{tr}}$ were $U_{\mathrm{sb}}$ (Fisher's exact, $n s$ ).

Almost all women had previous loss of an attachment figure. Neither the experience of past loss nor its lack of resolution appeared to increase the chance of being $U_{\mathrm{sb}}$ (see Table 2). Previous loss through early miscarriage was not associated with either the stillbirth experience being coded $U_{\mathrm{sb}}$ or having higher $U_{\mathrm{sb}}$ scores (see Table 3 ). However, previous elective termination of pregnancy was linked to higher $U_{\mathrm{sb}}$ scores (see Table 3).

Hypothesis 5: Is gestation of the stillbirth or recency of stillbirth associated with being $U_{s b}$ and is this accounted for by symptoms of grief?

Because subsequent analyses do not involve comparisons with control women, we used data from all 64 women in the stillbirth group, because including them makes the group more representative of the population of women who have experienced stillbirth. 
The gestation of the stillborn infant was not significantly different in women who were classified $U_{\mathrm{sb}}$ and women who were not (28.5 weeks, $S D=6.9$ vs. 26.2 weeks, $S D=7.1 ; t=$ $-1.3, d f=62, n s)$. However, women who had a third trimester loss had significantly higher $U_{\mathrm{sb}}$ scores than those who had a second trimester loss (Table 3).

The $U_{\mathrm{sb}}$ women were not significantly closer to loss (30.3 months, $S D=38.9$ vs. 36.4 months, $S D=27.7, t=.71, d f=62, n s)$. The correlation between the time since the stillbirth and the $U_{\mathrm{sb}}$ scores was not significant, $r(64)=-0.21, n s$. The 33 women who conceived within 12 months of stillbirth (i.e., $<21$ months from loss at the time of the AAI) had mean $U_{\mathrm{sb}}$ scores higher than the 31 who conceived $>12$ months from loss $(6.0, S D=1.8$ vs. 5.0, $S D=1.9 ; t=2.0, d f=62, p<.05)$, but the $U_{\mathrm{sb}}$ scores did not fall thereafter. The 17 women who conceived 12 to 36 months from loss $(4.9, S D=1.5)$ did not have higher scores than the 14 who conceived $>36$ months from loss $(5.2, S D=2.2)$.

Hypothesis 5A: Are symptoms of grief associated with the stillbirth related to being $U_{s b}$ ?

We found no significant association between $U_{\mathrm{o}}$ and depression scores or category. The association between anxiety and $U_{\mathrm{o}}$ scores was close to significance, $X_{U}=41.9$ ( $S D$ $=11.9), X_{\text {non- } U}=36.4(S D=10.9) ; t(55)=$ $-1.79 ; p<.06$. The correlation between $U_{\mathrm{sb}}$ and anxiety scores showed a trend toward significance, $r(58)=.23, p<.08$. It seems unlikely therefore that $U_{\mathrm{sb}}$ status can be explained as a consequence or a correlate of grief.

Because we found that those who had conceived within 12 months of the stillbirth had higher $U_{\mathrm{sb}}$ scores, we tested whether this could be associated with greater anxiety or depression. A univariate analysis of variance was performed and, although depression did not significantly contribute to the model $(F=$ $2.5 ; d f=1,54 ; n s)$, anxiety was a significant covariate $(F=4.4 ; d f=1,54 ; p<.05)$. With these covariates, conception within 12 months was no longer significant $(F=3.4 ; d f=1$, $54 ; p<.08)$. This is consistent with the model that anxiety may mediate unresolved scores.
Hypothesis 6: Does social support mitigate lack of resolution and if so, is it from the partner or from the woman's family?

Poor social support from the family of origin after stillbirth was associated with $U_{\mathrm{sb}}$ classification and higher $U_{\mathrm{sb}}$ scores. Fourteen $(93 \%)$ of 15 women who had poor support and $22(46 \%)$ of 48 who had good support were classified $U_{\mathrm{sb}}$, and women with low family support had higher $U_{\mathrm{sb}}$ scores (Table 3 ). Support from their partners after stillbirth did not predict $U_{\mathrm{sb}}$ status or scores.

Hypothesis 7: Do practices that encourage the mother to have increased contact with her stillborn child relate to whether she is likely to become $U_{s b}$ ?

We were interested in discovering if aspects of psychosocial management of stillbirth are effective in reducing the lack of resolution in relation to the loss. Three-quarters of women saw their stillborn baby, a little over half also held the body, and a little over half arranged a funeral. The probability of $U_{\mathrm{sb}}$ status and $U_{\mathrm{sb}}$ scores associated with these experiences are shown in Table 3. Our predictions were not supported by the findings. Although having seen the stillborn infant did not significantly relate to $U_{\mathrm{sb}}$ status or scores, holding the body was associated with higher $U_{\mathrm{sb}}$ scores and having had a funeral predicted both $U_{\mathrm{sb}}$ status and scores (Table 3).

\section{What is the combined importance of these background/intervention variables?}

To explore the relative importance of the eight variables that appeared to contribute to $U_{\mathrm{sb}}$ scores, we performed a multiple linear regression predicting the $U_{\mathrm{sb}}$ score from the experience of childhood trauma, trimester of loss, elective termination of pregnancy, holding the body, having a funeral, family support, whether the woman conceived again within 12 months, and anxiety scores.

In combination the eight variables yielded a multiple $R^{2}$ value of .55 ( $F=7, d f=8.46, p<$ $.0001)$. Three of the variables remained significant in the regression (see Table 4). These were the experience of childhood trauma, poor fam- 
Table 4. Results of multiple linear regression of factors contributing to $U_{s b}$ scores

\begin{tabular}{lrcc}
\hline \hline & B & $\beta$ & Signif. \\
\hline $\begin{array}{l}\text { Had childhood trauma } \\
\text { Previous termination of } \\
\text { pregnancy }\end{array}$ & 1.23 & .278 & .01 \\
$\begin{array}{l}\text { Trimester of loss } \\
\quad \text { 2nd or 3rd) }\end{array}$ & .58 & .176 & .09 \\
$\begin{array}{l}\text { Spielberger state anxiety } \\
\quad \text { score }\end{array}$ & .51 & .133 & .25 \\
$\begin{array}{l}\text { Loss to conception } \\
\quad<12 \text { months }\end{array}$ & .03 & .040 & .72 \\
$\begin{array}{l}\text { Support from family } \\
\text { Had funeral for SB } \\
\quad \text { infant }\end{array}$ & 1.69 & .012 & .92 \\
Held SB infant & 1.35 & .352 & .001 \\
\hline \hline
\end{tabular}

ily support after the loss, and having had a funeral for the stillborn infant (Table 4).

\section{Discussion}

We found that more than half of the women who had suffered stillbirth were unresolved in the subsequent pregnancy and, of these, all but one was unresolved with respect to the stillbirth. Being $U_{\mathrm{sb}}$ was predicted by the experience of childhood trauma/abuse, lack of support from the woman's family of origin after the stillbirth, and having a funeral for the stillborn infant.

The prevalence of the unresolved state of mind among this group is high, being only slightly lower than reported in psychiatric patients currently in treatment (Fonagy et al., 1996; Manassis, Bradley, Goldberg, Hood, \& Swinson, 1994; Patrick et al., 1994). This finding in a nonclinical population and the impossibility of blinding raters of the AAI caused us concern about the accuracy of our ratings. We were aware that being pregnant again after such a traumatic loss might reevoke a profound sense of loss and that in a nonpregnant population the rate of unresolved might well be lower. It seemed possible that the state of mind that leads to a classification of unresolved might be expected in a woman who has suffered stillbirth and is anxiously anticipating the next birth, inevitably remembering her loss, and possibly feeling some confusion between her feelings of longing for the lost child and the expected child. However, this does not in itself invalidate the findings, and we were reassured that our unresolved findings were valid by the high prevalence of infant disorganization in infants next born after stillbirth, where the Strange Situation was rated blind. We also found that unresolved was a strong predictor of infant disorganization, with $53 \%$ of mothers who were unresolved, and $9 \%$ of mothers who were not unresolved during pregnancy having disorganization in infants (Hughes et al., 2001). These figures are in line with previous reports of parent-infant matches (van IJzendoorn, 1995). Although it would be interesting to know if a nonpregnant group of similarly bereaved mothers would show such high levels of unresolvedness, the high level of disorganization in the infants confirms the relevance of working with a pregnant group.

Although the control group was carefully matched, more subject than control women were classified insecure in the 3-way AAI. This suggests that either insecure women are more likely to have a stillbirth or the anticipated birth after a stillbirth affects some women's representation of attachment, so those who usually have a secure representation might now show an anxious one. We have already reported that the infants in this group do not differ in their 3-way classification from their controls (Hughes et al., 2001). We suggest that some mothers with secure attachment representation become insecure when pregnant after stillbirth, but their interaction with their next-born child corresponds to their usual secure representation and allows the secure pattern to proceed in the infant. Studies that have examined the stability of the AAI report threecategory stability of between 70 and $90 \%$ over periods from 2 months to 4 years (Ammaniti, Speranza, \& Candelori, 1996; BakermansKranenburg \& van IJzendoorn, 1993; Crowell, Waters, Treboux, O'Connor, Colon-Downs, Feider, Golby, \& Posada, 1996; Sagi, van IJzendoorn, Scharf, Koren-Karie, Joels, \& Mayseless, 1994), and one study that evaluated three-category AAI pre- and postbirth reported 90\% stability (Benoit \& Parker, 1994). Mothers who have experienced stillbirth may 
withdraw emotionally from the next pregnancy to protect themselves from the pain of another loss (Kirkley Best \& VanDevere, 1986), and our findings support the notion that there may be some degree of instability in the representation of attachment and that change is especially likely when the subject is highly stressed in relation to attachment.

Groups were matched for educational level, age, and ethnic group, but detailed interviewing revealed greater social disadvantage among stillbirth than control women, even among some highly educated women. This is a potential confounding factor because women from lower socioeconomic groups are at higher risk for stillbirth (Office for National Statistics, 1998). On the other hand, it is known that grief following perinatal loss includes not only affective symptoms but also difficulty coping that may last for 2 or more years (Toedter, Lasker, \& Alhadeff, 1988). We cannot be certain why more women in the stillbirth group were relatively socially disadvantaged, but we argue that it is possible that this is consequence rather than a cause of stillbirth. In any case, although social disadvantage contributed to likelihood of being unresolved, it did not account for the difference in unresolved status between the two groups.

About a fifth of both stillbirth and control women reported experiencing physical or sexual abuse in childhood at the hands of an attachment figure. We found that childhood abuse predicted $U_{\mathrm{sb}}$, although additional loss of an attachment figure did not. We conclude that an earlier experience of extreme fear or helplessness in relation to an attachment figure renders the subject more likely to have difficulty thinking and speaking coherently in the AAI about later traumatic loss. However, we cannot establish retrospectively whether these abused children had been disorganized in relation to the attachment figure or whether they had experienced a childhood state of mind that might be described as unresolved. There is a known link between child maltreatment and disorganized attachment (Carlson, Cicchetti, Barnett, \& Braunwald, 1989; Lyons-Ruth, Connell, Grunebaum, \& Botein, 1990); and there has been interest in the possible effects of early disorganization on the adult representation of attachment, with postulated links between childhood disorganization, adult dissociative phenomena, and the unresolved state. One theory proposes that an unresolved parent would be prone to dissociative states and that interactions with the unresolved parent could create vulnerability to dissociative states in the child (Liotti, 1992). A long-term study offered empirical support, showing that children disorganized in infancy were susceptible to dissociative states in adolescence (Carlson, 1998). Finally, in a nonclinical sample of young adults, an association was found between parental loss around the time of the subject's birth and higher scores on an absorption scale (Hesse \& van IJzendoorn, 1998). Despite these findings, firm evidence of a link between childhood disorganization and adult vulnerability to becoming unresolved after loss or trauma remains elusive. It is tempting to suggest that the women in our study who suffered childhood abuse may have been disorganized with respect to attachment in childhood and this led to vulnerability to becoming unresolved after the traumatic loss of the stillbirth, but this remains speculative.

Women after stillbirth were more likely than control women to be unresolved in relation to childhood trauma. Because about the same number of women in the stillbirth and control groups had experienced trauma, we suggest the $U_{\text {tr }}$ state was triggered by the stillbirth and that the $U_{\text {tr }}$ state of mind may appear or reappear many years after the event. An alternative explanation is that women who were $U_{\text {tr }}$ were more likely to suffer stillbirth, which we think less probable. If the unresolved state in relation to a specific experience can appear or reappear after a time gap, this would support our proposal that the new pregnancy may have triggered the $U_{\mathrm{sb}}$ state in some women several years after the event and some women may have been resolved in the interim.

Bowlby's (1980) view was that "mourning" can be defined as "all the psychological processes, conscious and unconscious that are set in train by loss" and considered that "healthy mourning" was "the successful attempt of an individual to accept both that a change has occurred in his external world and 
that he is required to make corresponding changes in his internal, representational world and to reorganize ... his attachment behavior accordingly." Most work on recovery after bereavement has focused on the reduction of consciously painful symptoms of depression and to a lesser extent on coping with day to day living, and it is often suggested that 6-12 months is the usual time for recovery (Parkes, 1965; Peretz, 1970). Research on recovery from grief after stillbirth indicates that the recovery time may be as long as 2 years, although there are wide variations in normal (De Frain, Martens, Stork, \& Stork 19901991; Janssen et al., 1997; Lake, Knuppel, Murphy, \& Johnson, 1983). It was not surprising that we found that many women suffered high levels of symptoms of depression and anxiety during the pregnancy after stillbirth (Hughes et al., 1999), but depression was not associated with being $U_{\mathrm{sb}}$. The weak association between anxiety and $U_{\mathrm{sb}}$ disappeared when other factors were included in a multiple regression analysis. Therefore, it appears that the unresolved state and grief symptoms do not follow a parallel path of severity or recovery after stillbirth and this confirms that, at least in this population, the process of conscious emotional recovery is not the same as the process of becoming resolved.

Our finding that women who experienced poor family support after the loss were more likely to be unresolved is in line with Ainsworth and Eichberg's observation (1991) that feeling supported by family differentiated those who were resolved in their mourning from those who were not. For many women, stillbirth represents failure as a mother, perhaps particularly when the first child is stillborn. At this time she may desperately want reassurance from her family that she is not to blame, that they sympathize, and that she is loveable. A rejection at this time may reinforce a sense of personal unworthiness. Our data also suggest that support from her partner does not compensate for the lack of family support and reassurance.

Having had a funeral for the stillborn infant was associated with women being $U_{\mathrm{sb}}$ in the subsequent pregnancy. Although one might imagine that gestation could account for the decision to have a funeral and therefore for the increase in being unresolved, a multiple linear regression showed that having a funeral rather than the gestation of loss was the important predictor. We can only imagine this to have been an overwhelmingly distressing experience and that mothers might have difficulty in processing the memory. By contrast, parents chose to have a funeral and maybe those who were liable to become unresolved for some other reason also elected to have greater contact with the infant. Although practices promoting contact with the dead infant and creating memories are intended to help parents mourn the loss (Lewis, 1979), the finding of increases in the $U_{\mathrm{sb}}$ state indicates that for some women the experience of the funeral may not have the intended effect. The AAI transcripts showed that many women were concerned about the appearance of the child, some had thoughts about the grave being cold and about the baby being alone, and some visited the cemetery frequently, even daily. Some had an on-going sense of the date of the stillbirth as a birthday. We wanted to buy him a gravestone for his birthday, but we couldn't afford it. We suspect that practices that prolong or heighten emotional contact with the body may increase attachment to the dead child and intensify a profound sense of loss, thus leaving some women with images that haunt rather than comfort. Some women had a sense of having failed the child, and they seemed to try desperately to repair the situation as though the infant were alive. We put lots of things in her coffin and we wrote her a long letter just telling her about ourselves and giving her photographs and ... telling her how much she was wanted and if there was anything else we could do. . . .

Bowlby's conception of how an individual dealt with attachment trauma included a dynamic theory of defensive exclusion of painful material into "segregated systems" that are kept out of the consciousness. This notion was further developed by George, West, and Pettem (1999) who proposed that, when the attachment system is stressed by internal or external events that activate memories or associations connected with the loss, the defensive exclusion is liable to break down into specific forms of disorganization/disorientation. George and colleagues argue that the measure of "lack of resolution" in the AAI assesses a form of dys- 
regulation of segregated attachment systems. We think the pregnancy may have acted as a stressor that activated associations connected with the stillbirth, so that some women were unable to sustain the segregation. If the stillbirth was represented as another experience of pain, fear, and helplessness, it may have acted associatively as a stressor in relation to childhood trauma, which also became desegregated. We emphasize, however, that there was no question of a problem with memory for the events of the stillbirth. None of the women in the study had any difficulty remembering, but not all were disorganized/disorientated in their speech. On the basis of the relationships we have found between the unresolved state and other factors, we would make a case for the unresolved state as a motivated and defensive state of mind. We propose that the unresolved state of mind after stillbirth represents a mechanism to protect a woman from full acceptance of the loss. We also argue that some factors associated with liability to the unresolved state (poor family support and abuse) may be associated with poor selfesteem and a sense of being blameworthy. These may increase a sense of causality and make the woman fearful of fully accepting her loss and thus recognizing the damage that she irrationally feels herself to have done. We think that when a woman maintains false (dead-not dead) beliefs she allows herself the luxury of illusion that she can have an on-going relationship with her child. I always say you know, sorry you came so soon you know I mean you arrived so soon and we couldn't keep you, I say well you know, whatever, anything I did wrong. . . I told her to come back you know maybe she'll be happy to be my baby again. In addition, when a woman became absorbed in a moment by moment reliving of the events surrounding the loss, we thought this indicated she was maintaining the memory intact and very much in the present. We saw little indication that women wanted to let go of these ways of holding onto the infant, and some openly stated a wish to keep the re-

\section{References}

Ainsworth, M. D. S., \& Eichberg, C. (1991). Effects on infant-mother attachment of mother's unresolved loss of an attachment figure, or other traumatic experi- lationship alive. Sometimes I feel guilty toward Stevie, I think, I hope that he doesn't think we're going to forget about him, which we wouldn't, he'll always be our first baby.

\section{Shortcomings of the Study}

Although the selection of a homogeneous group was an important part of the study, we recognize that, as a result, some of our conclusions may not be generalizable. In addition, as already mentioned, the fact that the women were pregnant may have changed their states of mind with respect to the stillbirth, and we do not know if the same result would have been found in a nonpregnant group of women who had experienced stillbirth. It is always desirable that the coders of the AAI are blind to whether the individual is a member of the index or control group. Blinding could not be achieved in this study, and it remains an unavoidable weakness. However, the strong association already reported between maternal unresolved status and infant disorganization (Hughes et al., 2001) offers some validation for the unresolved coding.

Our control group was not a perfect match: the stillbirth mothers had had previous experience of childbirth and some had had previous miscarriage or termination of pregnancy as well, whereas control mothers were having a first pregnancy and first child. The ideal would be to have additional control groups, for example, women having a second normal pregnancy, nonpregnant women who had a stillbirth, and nonpregnant women matched on a variety of demographic characteristics who did not have a stillbirth. In addition, our numbers are relatively small and the study has limited power to detect differences that might be associated with attachment classifications. This means that, in particular, some of the negative results reported in this study should be treated with caution. ence. In C. M. Parkes, J. Stevenson-Hinde, \& P. Marris (Eds.), Attachment across the life cycle (pp. 160183). London/New York: Tavistock/Routledge. 
Ammaniti, M., Speranza, A. M., \& Candelori, C. (1996). Stability of attachment in children and intergenerational transmission of attachment. Psychiatria dell 'Infanzia e dell'Adolescenza, 63(3), 13-32.

Bakermans-Kranenburg, M. J., \& van IJzendoorn, M. H. (1993). A psychometric study of the adult attachment during late childhood and early adolescence: Reliability and discriminant validity. Developmental Psychology, 29, 870-889.

Bakermans-Kranenburg, M. J., Schuengel, C., \& van IJzendoorn, M. H. (1999). Unresolved loss due to miscarriage. Attachment and Human Development, 2, 157-170.

Benoit, D., \& Parker, K. C. H. (1994). Stability and transmission of attachment across 3 generations. Child Development, 65, 1444-1456.

Bowlby, J. (1980). Attachment and loss: Vol. 3. Loss: Sadness and depression. London: Hogarth.

Bowlby, J. (1982). Attachment and loss: Vol. 1. Attachment. London: Hogarth. (Original work published 1969)

Carlson, E. A. (1998). A prospective longitudinal study of disorganised/disorientated attachment. Child Development, 69, 1107-1128.

Carlson, V., Cicchetti, D., Barnett, D., \& Braunwald, K. (1989). Disorganized/disorientated attachment relationships in maltreated infants. Developmental Psychology, 25, 525-531.

Cox, J. L., Holden, J. M., \& Sagovsky, R. (1987). Detection of postnatal depression: Development of the Edinburgh Postnatal Depression Scale. British Journal of Psychiatry, 150, 782-786.

Crowell, J., Waters, E., Treboux, D., O'Connor, E., ColonDowns, C., Feider, O., Golby, B., \& Posada, G. (1996). Discriminant validity of the Adult Attachment Interview. Child Development, 67, 2584-2599.

De Frain, J., Martens, L., Stork, J., \& Stork, W. (19901991). The psychological effects of stillbirth on surviving family members. Omega, 22, 81-108.

Fonagy, P., Leigh, T., Steele, M., Steele, H., Kennedy, R., Mattoon, G., Target, M., \& Gerber, A. (1996). The relation of attachment status, psychiatric classification, and response to psychotherapy. Journal of Consulting and Clinical Psychology, 64, 22-31.

Fonagy, P., Steele, H., \& Steele, M. (1991). Maternal representations of attachment during pregnancy predict the organization of infant-mother attachment at one year of age. Child Development, 62, 891-905.

George, C., West, M., \& Pettem, O. (1999). The adult attachment projective: Disorganisation of adult attachment at the level of representation. In J. Solomon \& C. George (Eds.), Attachment disorganisation (pp. 291317). New York: Guilford Press.

Harris, B., Huckle, P., Thomas, R., Johns, S., \& Fung H. (1989). The use of rating scales to identify post-natal depression. British Journal of Psychiatry, 154, 813-817.

Heller, S. H., \& Zeanah, C. H. (1999). Attachment disturbance in infants born subsequent to perinatal loss: aA pilot study. Infant Mental Health Journal, 20, 2 , 188-199.

Hesse, E., \& van IJzendoorn, M. H. (1998). Parental loss of close family members and propensities towards absorption in offspring. Developmental Science, 1, 299-305.

Hesse, E., \& van IJzendoorn, M. H. (1999). Propensities towards absorption are related to lapses in the monitoring of reasoning or discourse during the Adult At- tachment Interview: A preliminary investigation. Attachment and Human Development, 1, 67-91.

Hughes, P., Turton, P., \& Evans, C. D. H. (1999). Stillbirth as a risk factor for anxiety and depression in the next pregnancy: Does time since loss make a difference? British Medical Journal, 318, 1721-1724.

Hughes, P., Turton, P., Hopper, E., McGauley, G. A., \& Fonagy, P. (2001). Disorganised attachment behaviour among infants born subsequent to stillbirth. Journal of Child Psychology and Psychiatry, 42, 791-801.

Janssen, H. J. E. M., Cuisinier, M. C. J., de Graauw, K. P. H. M., \& Hoogduin, K. A. L. (1997). A prospective study of risk factors predicting grief intensity following pregnancy loss. Arch Gen Psychiatry, 54, 56-61.

Kirkley Best, E., \& VanDevere, C. (1986). The hidden family grief: An overview of grief in the family following perinatal death. International Journal of Family Psychiatry, 7, 419-437.

Lake, M., Knuppel, R., Murphy, J., \& Johnson, T. (1983). The role of a grief support team following stillbirth. American Journal of Obstetrics and Gynecology, 146, 877-881.

Lee, D. T. S., Wong, C. K., Ungvari, G. S., Cheung, L. P., Haines, C. J., \& Chung T. K. H. (1997). Screening psychiatric morbidity after miscarriage: Application of the 30-item general health questionnaire and the Edinburgh postnatal depression scale. Psychosomatic Medicine, 59, 207-210.

Lee, D. T. S., Yip, S. K., Chiu, H. F. K., Leung, T. Y. S., Chan, K. P. M., Chau, I. O. L., Leung, H. C. M., \& Chung, T. K. H. (1998). Detecting postnatal depression in Chinese women. Validation of the Chinese version of the Edinburgh postnatal depression scale. British Journal of Psychiatry, 172, 433-437.

Lewis, E. (1979). Mourning by the family after stillbirth or neonatal death. Archives of Diseases of Childhood, $54,303-306$.

Liotti, G. (1992). Disorganised/disorientated attachment in the aetiology of the dissociative disorders. Dissociation, 5, 196-204.

Lyons-Ruth, K., Connell, D., Grunebaum, H., \& Botein, S. (1990). Infants at social risk: Maternal depression and family support services as mediators of infant development and security of attachment. Child Development, 61, 85-98.

Main, M., DeMoss, A., \& Hesse, E. (1991). Unresolved/ disorganised/disoriented state of mind with respect to experiences of loss. In M. Main \& R. Goldwyn (Eds.), Adult attachment scoring and classification systems (pp. 103-133). Unpublished manuscript, University of California at Berkeley.

Main, M., \& Goldwyn, R. (1985-1995). Adult attachment scoring and classification system. Unpublished manuscript, University of California at Berkeley, Department of Psychology.

Main, M., \& Hesse, E. (1990). Parents' unresolved traumatic experiences are related to infant disorganised status: Is frightening and/or frightened behaviour the linking mechanism? In M. T. Greenberg, D. Cicchetti, \& E. M. Cummings (Eds.), Attachment in the preschool years: Theory, research and intervention ( $\mathrm{pp}$. 161-182). Chicago: University of Chicago Press.

Main, M., \& Hesse, E. (1992). Disorganised/disorientated infant behaviour in the Strange Situation, lapses in the monitoring of reasoning and discourse during the parent's Adult Attachment Interview and dissociative states. In M. Ammaniti \& D. Stern (Eds.), Attachment 
and psychoanalysis (pp. 86-140). Rome: Gius, Laterza and Figli.

Main, M., Kaplan, N., \& Cassidy, J. (1985). A move to the level of representation. Monographs of the Society for Research in Child Development, 50(1-2, Serial No. 209), 66-104.

Main, M., \& Solomon, J. (1986). Discovery of a new, insecure-disorganised/disorientated attachment pattern. In M. Yogman \& T. B. Brazelton (Eds.), Affective development in infancy (pp. 95-124). Norwood, NJ: Ablex.

Main, M., \& Solomon, J. (1990). Procedures for identifying infants as disorganised/disorientated during the Ainsworth Strange Situation. In M. T. Greenberg, D. Cicchetti, \& E. M. Cummings (Eds.), Attachment in the pre-school years: Theory, research and intervention (pp. 121-160). Chicago: University of Chicago Press.

Manassis, K., Bradley, S., Goldberg, S., Hood, J., \& Swinson, R. P. (1994). Attachment in mothers with anxiety disorders and their children. Journal of the American Academy of Child and Adolescent Psychiatry, 33, 1106-1113.

Murray, D., \& Cox, J. (1990). Screening for depression during pregnancy with the Edinburgh depression scale (EPDS). Journal of Reproductive and Infant Psychology, 8, 99-107.

Office for National Statistics. (1998). Birth statistics 1996, England and Wales (Series FMI, No. 25). London: Office for National Statistics.

Parkes, C. M. (1965). Bereavement and mental illness, Part III. A classification of bereavement reactions. British Journal of Medical Psychology, 38, 13-26.

Patrick, M., Hobson, R. P., Castle, D., Howard, R., \& Maughan, B. (1994). Personality disorder and the mental representation of early social experience. Development and Psychopathology, 6, 375-388.

Peretz, D. (1970). Reaction to loss. In B. Schoenberg, A. C. Carr, D. Peretz, \& A. H. Kutscher (Eds.), Loss and grief: Psychological management in medical practice (pp. 20-35). New York: Columbia Press.

Pop, V. J., Komproe, I. H., \& Van Son, M. J. (1992). Characteristics of the Edinburgh post natal depression scale in The Netherlands. Journal of Affective Disorders, 26, 105-110.

Royal College of Obstetricians and Gynaecologists. (1985). Report of RCOG Working Party on the Man- agement of Perinatal Deaths. London: Chameleon Press Ltd.

Rutter, M., \& Quinton, D. (1977). Psychiatric disorderEcological factors and concepts of causation. In $\mathrm{H}$ McGurk (Ed.), Ecological factors in human development (pp. 135-157). Amsterdam: North-Holland.

Sagi, A., van IJzendoorn, M. H., Scharf, M., KorenKarie, N., Joels, T., \& Mayseless, O. (1994). Stability and discriminant validity of the Adult Attachment Interview: A psychometric study in young Israeli adults. Developmental Psychology, 30, 771-777.

Schuengel, C., Bakermans-Kranenburg, M. J., \& van IJzendoorn, M. H. (1999). Attachment and loss: Frightening maternal behaviour linking unresolved loss and disorganised infant attachment. Journal of Consulting and Clinical Psychology, 67, 54-63.

Spielberger, C. D., Gorsuch, R. L., \& Lushene, R. (1970). Test for the State-Trait Anxiety Inventory. Palo Alto, CA: Consulting Psychologists Press.

Stuart, S., Couser, G., Schilder, K., O'Hara, M. W., \& Gorman, L. (1998). Postpartum anxiety and depression: Onset and comorbidity in a community sample. Journal of Nervous and Mental Disease, 186 $420-424$.

Toedter, L. J., Lasker, J. N., \& Alhadeff, J. M. (1988). The perinatal grief scale: Development and initial validation. American Journal of Orthopsychiatry, 58 , 435-449.

van IJzendoorn, M. H. (1995). Adult attachment representations, parental responsiveness, and infant attachment: A meta-analysis on the predictive validity of the Adult Attachment Interview. Psychological Bulletin, 117, 387-403.

van IJzendoorn, M. H., \& Bakermans-Kranenburg, M. J. (1996). Attachment representations in mothers, fathers, adolescents, and clinical groups: A meta-analytic search for normative data. Journal of Consulting and Clinical Psychology, 64, 8-21.

van IJzendoorn, M. H., Feldbrugge, J. T. T. M., Derks, F. C. H., deRuiter, C., Verhagen, M., Philipse, M., Van der Staak, C. P. F., \& Riksen-Walraven, M. (1997). Attachment representations of personality-disordered criminal offenders. American Journal of Orthopsychiatry, 67, 449-459.

Zeanah, C. (1989). Adaptation following perinatal loss: A critical review. Journal American Academy of Child and Adolescent Psychiatry, 28, 467-480. 